\title{
Journal club: An Important Teaching-Learning Activity
}

ABM JAMAL

\begin{abstract}
Summary:
Journal club is an important teaching learning activity of educational institutions and thus improving medical education of the country. It is directly related to improving patients outcome of one,s own department or institution. There is increasing demands to practice effectively medical science at highest stakes. A formal journal club facilitates discussing and evaluating new research and its application to practice and improving patient care. However many a times, journal club fails to achieve its role and a superficial discussion on clinical aspects distracts its aims and objectives. The advantages of using a journal club are that you and
\end{abstract}

\section{Introduction:}

Journal clubs are a well-recognized quality improvement strategy used by health practitioners to critique and keep up-to-date with relevant health literature. A number of authors reported that sir William Osler started the first recorded journal club in Britain in 1875 as a way of sharing educational resources ${ }^{1,2}$. He encouraged journal club attendees to apply their updated knowledge from participation of journal club. From its inception, goal was to share current knowledge and translate it into evidence based patient care. There are many advantages of participating in a journal club, including keeping a breast of new knowledge, promoting awareness of current research findings, hearing to critique and appraise research becoming familiar with the best current clinical research and encouraging research utilization. ${ }^{3}$ It is therefore an ongoing challenge for clinicians to design and maintain a stimulating, educational and sustainable journal club format that assists the participants to date with the literature and to translate journal. The outcomes of the research may be presented by the individual student or by the group as a report, a poster, a videotape in a journal club or in a written material. ${ }^{4}$

Address of Correspondence: Dr. Abul Bashar Md. Jamal, Associate Prof. of Surgery, Dhaka Medical College, Cell: 01819230009, E-mail_abmjamal2003@yahoo.co.in.

Received: 18 September, $2014 \quad$ Accepted: 12 July, 2015 your peers can keep current with new transplant knowledge, learn to facilitate the strength of the evidence, promote implementation of new knowledge into practice, and improve patient outcomes. A journal club has been defined an educational meeting in which a group of individuals discuss current articles, providing a form for a collective effort to keep up with the literatures Key words: Journal club, Evidence based practice, Medical education.

Key words: Journal club, Teaching-learning Activity, Medical education.

(J Banagladesh Coll Phys Surg 2015; 33: 213-217)

\section{Objectives of journal club Presentation}

The general purpose of a journal club is to facilitate the review of a specific research study and to discuss implications of the study for clinical practice. This is an important ways in which success can be measured as a clinical teacher and may choose to specialize in any of a number of paths to progression. Journals are naturally biased towards research. What most journal editors are hoping, frequently in vain, to see when they approach a pile of new submissions is innovative, ground-breaking research which will be frequently read and widely cited. Although, as we have said, there are many valid products of excellence in medical education, the majority of journals cannot space for people to display their skills in clinical teaching unless the work they have submitted is: original, educationally important, academically rigorous. $^{4}$

a. Education-The main educational goals are to teach the trainee about research activity, presentation skills, computer and internet literacy, critical analysis of literature. The trainee and trainers can also develop patient management skill through modern and up to date concepts of medical science. They can also find a way out for self directed learning approach.

b. Evaluation of trainee- In many countries, now a days residency program is used as a mean to evaluate the trainee as their competency. Still many 
centers following the earlier systems of fellowship program like BCPS. Running a well planned Journal club can be used as a useful tool to evaluate residents presentation skills, attitudes, punctuality, quality of care and ultimately the progress in clinical medicine. Though overall progress of the trainee can be assessed by other means, still journal club can be added to those.

c. Evaluation of quality service- Journal articles published within and outside the institution can be discussed in journal club will be beneficial for service improvement of a particular institute. Sometimes comparison with similar institute is also possible through discussion from publication done by other institute.

d. Detection of adverse events- Though discussion in journal club has got limited scope for discussion about issues on particular patient but in relation to example cited in a situation it can be drawn and put forward in front of the audience and make a conclusion thereafter.

e. Social Interaction-Journal club discussion provides a unique opportunity for trainee and faculty members to socialize. In the survey of journal club most of the participants pointed out that it is an important tools for daily social events for them.

f. Faculty development- Through journal club presentation faculty development program can be strengthen and individual faculty can get benefit from others. Participation of each faculty in journal club will motivate their involvement in research. Moreover, good number of teacher will get benefit from each other through discussion. ${ }^{6}$

\section{Structure of journal club presentation}

The following organization are commonly observed in journal club.

a. Arrangement-Usually done once in a week but can be complemented more than that. Better , if it resume early in the morning as a first incident of the day so that fresh mind will contribute more. In some center where more than one unit works together, journal club can be arranged many times in a week or even at evening time. In Bangladesh , most center it runs once in a week and very early in the morning. Usually the presentation part take about 15-20 minutes followed by 30 minutes discussion time. It should be remembers that open and free discussion is the heart of the journal club. Many a times it has been observed that discussion runs among the most senior faculty members while trainee fails to contribute their.

b. Sitting arrangement- This is a neglected issue in journal club presentation session. Set your arrangement in a circular manner or semicircular manner so that everybody sees each other from any corner. The facilitator, chair person, timekeeper and presenter will place themselves in a position from where every participant can easily communicate with each other. Choose where you are going to take position yourself in the theatre and whether you are going to stand, sit or walk around. Do you wish to be behind a podium or table or nearer , and so more able to make contact with, the audience? Wherever you are, be sure you are near the microphone and that it is at the correct height for you, and of course be sure, you are not obstructing the audience's view of the projector screen.

c. Space-although educational programme of excellence have flourished without the benefit of a dedicated facility, there is no doubt that the latter makes possible a more comfortable and predictable programme of curricular activities. In institutions where small-group teaching methods are used regularly, these group sizes and activities should be considered along with other activities. ${ }^{7}$

d. Record keeping-Record keeping done for different purposes. For educational purposes, as well as for research activities also. A register has been maintained to keep the content coverage as well as future recommendation for weak areas need to cover. Data and other materials should be kept in a suitable place for the scope of creation of future areas.

\section{Formats of Journal club}

Journal club in every institute does its own structure. Despite that there should be some common things that overlap the individuality. Moreover, the objectives of journal club should be keep in mind while planning a journal club session. Its better to form a committee for journal club for smooth running of such. The article selection is an important component of journal club and 
it should be done well ahead of time. The article can be circulated among the participants and displayed in a front place so that everybody get an opportunity to prepare themselves by studying relevant sources .

While presenting a journal club through PowerPoint presentation over a screen so that audience can follow the talk.

Table-I

\section{Criteria for analysis}

\begin{tabular}{ll}
\hline Participants & $\begin{array}{l}\text { Number of participants } \\
\text { Field of participants }\end{array}$ \\
Intervention & Group leader \\
& Preparation(pre-reading) \\
& Frequency of meeting \\
& Setting \\
& Mandatory attendance \\
& Article choice \\
& Clinical focus \\
& Original article \\
Format & Structured evaluation processes \\
& Faculty supervised \\
& Internet based \\
& Time of day noted \\
& Formal process \\
& Food provided \\
& Results reported \\
Results & Specific outcomes tested \\
& Statistical significance \\
\hline
\end{tabular}

\section{Select a provocative article}

Too good choices that you pulled as a result of an encounter with a particular patient and articles that have been published recently dealing with a clinical problem we commonly encounter.

It should report a original research paper which contains all the components of a scientific paper. Review articles are not suitable many a times. And those article which does have a methods section. Meta-analyses, decision analyses and cost-effectiveness analyses are well, but they are harder to assess critically because the results often depend on whether you can trust the authors and underlying assumptions.

\section{Outline of the content of the article}

The same sort of learning that allows one to get better at obtaining relevant information from a patient, organizing it, and presenting it to others applies to reading journal articles as well. After using the structure below to review the article yourself, lead the journal club participants through it. Write the main headings once at a time on the board, explain what they mean, and get the participants to fill in the data from the paper. The elements of a study, analogous to the presenting complaints, presenting illness, past illness and so on are:

A. Authors and funding source: This is analogous to the "identifying information and source of history". It's a good idea to start with these items so you don't forget them later. Anyone can search their previous works and able to be mention here.

B. Research question: What is the question this study was designed to answer? Sometimes it helps to picture a clinical situation you'll be better able to handle if the study is valid. Often the last line of the abstract gives the authors answer to the research question.

C. Study design: What type of study is this? Randomized blinded trial? Cohort study? Casecontrol study? Cross-sectional study? Case series? The presenter must know this and will be able to mention whenever asked in the presentation.

D. Study subjects: Who were in the study included? What are the selection criteria? How were they had been selected. Is there any process of blinding?

E. Study period and place: Study place and period is usually clearly mentioned in any article. But if not mentioned you have to find out it and mention clearly in separate headings.

F. Data collection, editing, processing etc: After formation of questioners does any pretesting done or not? What are the process of data collection , interpretation, editing and formulation performed. Data can be retrieved by various means and they can be calculated thereafter.

G Variables: The variables used in the paper and also their interpretation can be plotted and should be correlated with those of objectives. 
H. Results: What did they find? Don't just mention about each and every table and figure. Also you have to mention the lesson behind main findings of those. Make sure you consider not just statistical significance, but the effect size, relative size and odds ratio of each.

I. Conclusion and recommendation: This part not only include the authors write up but also the presenter's recommendations and how the presenting department will utilize those findings in near future. ${ }^{8}$

\section{Discussion:}

Discussion after the total presentation should be structured and well controlled. The facilitator should take the whole control of this part and he has to conduct, motivate for participation and engage each participant. That's why it is called “Club” not a seminar. It's a easy task to distribute some of the copy of the article 10 days before, among 10 similar member of the club and ask them to get prepare for contribution in the discussion. You can raise opinion pole or voting on particular issue like a meeting in a cricket or debate club. The co-ordinator can also place a copy of the article in a board in front of club room day before scheduled time so that any interested person can come forward and join. You can use internet for easy access to all of them. Remember, no scientific study is absolutely perfect. When someone suggests possible problem, you need to discuss whether this is something that is really important, and how it would affect the results. ${ }^{9}$

\section{Wrapping Up}

The most important part is of course the "bottom line". If you don't utilize the findings of any result, it is futile to run a journal club. Sometimes it is seen that, the delivery of speech from senior persons or dignitary get preference than the actual message of the journal club. ${ }^{10}$ This should be avoided.

\section{Importance of Journal club as a teaching-learning process}

Question may arise or may not arise as well : Why we should run an effective journal club? Is it just only to fulfill the desire of faculty members or completion of requisition of the pertinent authority ? Or someone may think I will do research work and publish it accordingly, I have to go through that and learn the necessary things through courses or books!
First thing we can consider that it's a teaching-learning process not only for trainee, students or staff but also as a part of faculty development program. Whenever we called it's a faculty development, it means not only a certificate based "one time show" or it is an achievement. Staff development or faculty development activities have been designed to improve teacher effectiveness at all levels of the educational continuum (e,g. undergraduate, postgraduate and continuing medical education and diverse programmes have been offered to healthcare professional in many settings. For running a good journal club, it is important that faculty members are clear about goals and objectives of this program. They have to participate in it actively and provide feedback regularly. Frequently it has been observed that faculty members present in the journal club keep silent listener and whenever talks at last stage , mainly share their personal experiences regarding that topic not the article itself. This is a serious misuse of the effort and faculty should keep an eye on it ${ }^{11}$.

Second things we have to consider that it's a good option for developing team building. In journal club we can organize a group, make a team and can provide feedback regarding effective team building. A article can be presented by many student and every part can be distributed among them to discuss, to develop, to collect from other resources and even to answer the question during presentation. Teams are collections of people who must rely on group collaboration if each member is to experience the optimum of success and goal achievement ${ }^{12}$. Each person in a team will be the focal person and should have a chance to read his or her answers to preparatory questions. Each person should have ample time to think, answer and participate in a team.

Journal club presentation can be used as monitoring and evaluation of training of the trainee. Educational evaluation is the systemic appraisal of the quality of teaching and learning. Maintaining log book and time to time evaluation is a good way of appraisal. Journal club presentation and reporting on journal article is a strong tool for such program. One thing that has to be keep in mind is that critical analysis by the faculty members and adequate effective feedback is not an optional things but it's a must do process ${ }^{13}$.

Management has been defined as the purposeful and efficient use of resources. So, management of journal 
club session is an important opportunity to learn how to run a course, module, center or institution. Participation in journal club by adequate number of student, faculty and guests is an important reflection of management skill of the unit or department. Also the quality of the club is a reflection in such cases ${ }^{14}$.

Presentation is an art which must be learnt to a competent degree by all persons who are involved in the process of imparting knowledge, be it to children or adults. When a presenter tries to communicate it is important to have a certain degree of expertise at the subject itself, a grasp of the language and also the ability to communicate ${ }^{15}$. Hearing alone may not create a firm impression on the minds of those involved in learning process. Catering to the other senses, in addition, lends credence to the saying "what I hear I forget, what I see I remember and what I do I learn”. Presentation in public places is the ultimate way of learning and it's a real reflective learning. Presentation skill can be best tested in such a way and this opportunity should not misuse by any means ${ }^{16}$.

National Goal and Objectives of MBBS course has been designed in Bangladesh in such a way that to produce competent, compassionate, reflective and dedicated health care professional who but at the same time acquire firm basis for future training, service and research at both national and international level. Also they have a commitment to keep their knowledge and skill up-todate through "Continuous Professional Development " all through their professional life ${ }^{17}$.

\section{Conclusion:}

Journal club is an important teaching-learning activity for the trainee. Its also useful to rememorize the research aspects of the faculty and a option for boost up for future researcher. But It should be done in a scientific way and the research aspects should be highlighted in every session.

\section{References:}

1. Deenadayalan y, Grimmer-Somers K, Kumar S. How to run an effective journal club: a systematic review. J of evaluation in clinical practice 2008; 14:896-911.

2. Kirkhhoff KT, Berk SL. Using the journal club as a component of the research utilization process. Heartlung 1995; 24: 246-250.

3. How to Develop a successful Journal Club. Intenational Transplant Nurse Society, 2012.

4. Begum T. Projects and dissertation. In: Concepts of Medical Education. Tahmina Begum. $1^{\text {st }}$ ed. Dhaka. 2013. Page 244-247.

5. Bligh J, Brice J. Research and publication. In : A practical guide for Medical Teacher. Den JA, Harden RM. $2^{\text {nd }}$ ed. 2005.Elsvier, Edinburgh. Page 412-420.

6. Mowla MM. Morning report: A tool for improving Medical Education. J Bangladesh Coll Phy Surg 2013; 30: 91-95.

7. Adamo G, Dent JA.Teachinhg in clinical skill center. In : A practical guide for Medical Teacher. Dent JA, Harden RM. $2^{\text {nd }}$ edi. 2005.Elsvier, Edinburgh. Page 67-70.

8. BMJ carriers about successful journal club. (13 October 2007). http://carreers.bmj.com/carreer/ view/article.

9. Newman T. Suggestion for leading journal club. Access through website( 2 December 2013).

10. Klienpell R. Rediscovering the value of the journal club. American journal of critical care2002; 11(5): 412-414.

11. Steinert Y, Nasmith I, Mcleod P, Conochie L. A teaching scholars program to develop leaders in medical education. Academic Medicine 2003; 78:142-49.

12. Dyer WG. In: Team Building, Issues and Alternatives.Addison-wesley.1987 $2^{\text {nd }}$ ed. Pp-3-5.

13. Begum T. Concepts of Medical Education. Asian color. Dhaka, 2013. Pp-235-40.

14. MacGrath EH. Basic Management Skills for All. $4^{\text {th }}$ edition. New Delhi. Prentice hall of India Pvt. 1996. PP120-29.

15. Medical Education Technology Workbook. Participants Handbook.2003. CMC, Vellore. India.

16. Lowman J. Mastering the techniques of teaching. 1984. NewYork, USA.

17. Curriculum for Under-graduate Medical Education in Bangladesh- update 2012. BMRC, Dhaka.2012. 